Article

\title{
Teachers' Thoughts on Student Decision Making During Engineering Design Lessons
}

\author{
Helen Meyer \\ School of Education, University of Cincinnati, Cincinnati, OH 45221, USA; helen.meyer@uc.edu
}

Received: 31 October 2017; Accepted: 9 January 2018; Published: 11 January 2018

\begin{abstract}
In this paper, I share the results of a study of teachers' ideas about student decision-making at entry into a professional development program to integrate engineering into their instruction. The framework for the Engineering Design Process (EDP) was based on a Challenge-Based Learning (CBL) model. The EDP embedded within the CBL model suggests teachers should provide opportunities for students to make decisions throughout the design process. The differentiation consolidation decision-making framework was used to understand the decision-making process. Study data was gathered from 16 teacher participants, interviewed and surveyed at entry into the program. The data were analyzed to understand the kinds of decision-making activities the teachers' identified as possible for students to make based on eleven engineering design scenarios and the teachers' current use of, and confidence in applying, lessons that engaged students in decision-making. The results indicated the teachers most frequently identified students that engaged in stage one decisions-making activities, i.e., problem identification and clarification. When the teachers discussed stage two and stage three decision-making activities, they most frequently discussed general problem solving or design process type activities with little differentiation of specific details of how the decision-making was to take place. In addition, in most cases teachers did not mention teaching or supporting student decision-making strategies.
\end{abstract}

Keywords: engineering-design; problem-based learning; teacher decisions; student decision-making

\section{Introduction}

We are now into the second decade of the 21st century and education systems are still working to understand exactly what needs to happen for teachers to become confident 21st century teachers. We know that a 21st century education should be a key component in preparing citizens to be active, engaged, and informed decision makers and citizens. If students are to take on this role, they need experience making and implementing decisions of consequence as part of their education. One mechanism suggested to improve decision-making experiences and 21st century skills for students is the instructional strategy Problem-Based Learning (PBL). Cone describes PBL as "an inquiry-based approach to prepare students to be productive citizens in a global society [1]. A PBL strategy is suggested in the A Framework for K-12 Science Education [2] as part of the inclusion of engineering into the science standards. In the Framework, engineering is broadly defined as: "any engagement in a systematic practice of design to achieve solutions to particular human problems" [2] (p. 11). The systematic process of solving problems in engineering is the Engineering Design Process (EDP). The EDP is a systematic way for students to work through the complex problems used to drive PBL activities in the sciences which also integrate mathematics. EDP and PBL, if done correctly, require- students to make decisions about how to proceed as they work towards a design or solution. These instructional strategies hold at their center the ideal of 'student-centered learning', which Gordon, Rogers, Comfort, Gavula, \& McGee characterized for PBL instruction as learning where "the learners are responsible for determining their own learning needs and conducting inquiries according to their 
own personal learning preferences [3] (p. 171)." As such, engineering lessons provide opportunities to determine the kinds of decision-making activities teachers identify for their students.

It is clear the potential for students to learn and practice complex decision-making exists when teachers engage their students in engineering design instruction. However, it is unclear what decisions teachers actually allow their students to make during EDP learning activities. For many teachers, turning decision-making over to students is a challenge. Although it is difficult to find research with an explicit focus on the kinds of decisions teachers are comfortable allowing their students to make, it is implicitly addressed on a regular basis. Teachers' comfort with students as decision-makers is an implied barrier in years of STEM education reform literature [4]. Richardson and Placier's review of the teacher change literature provides ample evidence of teachers' discomfort with student decision-making and the kinds of decisions students should be making [5]. All of this work predates the current emphasis on PBL and EDP. However, as we are pushing teachers to be more open to PBL and EDP instructional strategies, there is little research explicitly designed to understand what teachers believe about empowering students to make important decisions that impact the course of instruction. The research reported takes a step towards this by exploring the questions:

A How confident are teachers implementing lessons that engage students in decision-making activities?

B What potential decision-making activities do teachers identify in engineering design lessons?

In the remainder of this chapter, I discuss the essential ideas detailed in past research on teachers' beliefs and how beliefs influence teachers' instructional decisions. I follow this with a more detailed discussion of the decision-making literature and resultant frameworks and processes defined from this work, which informed my analytical framework. I then turn to the specifics of this study including context, participants, methods, results, and findings. Finally, I discuss the implications of the kinds of decisions the science and mathematics teachers believed their students should be allowed to make and what this means for preparing teachers to work in 21st century classrooms.

\section{Theoretical Background}

\subsection{Teachers' Beliefs}

The study of teacher beliefs is not a new research area. In 1996, Virginia Richardson reviewed the extensive existing literature on teacher beliefs and its overlap with research on teacher knowledge [6]. In this work, she created the distinction between the knowledge and beliefs teachers bring to their practice. Richardson claimed teacher knowledge must meet a standard of external truth and be understood in relationship to these external standards. Beliefs, however, are not justified by externally accepted standards; rather, individuals seek to internally align their beliefs with each other and hopefully with their practice. However, there is literature that indicates that teachers' beliefs are not always internally consistent, nor are they always aligned with teachers' knowledge statements $[7,8]$. We do know that the knowledge and beliefs held by teachers serve to guide their actions in the classroom, and teachers do not necessarily distinguish between when they are acting on their knowledge of teaching or their beliefs about teaching.

The teacher beliefs research has been used to guide and assess teacher professional development activities. Guskey delineated three important aspects to consider: (a) teachers' beliefs affect the actions they take in the classroom; (b) they are difficult to change; and (c) without changing teachers' beliefs it is difficult to change teachers' practices [9]. The teacher belief and teacher change literature served as the theoretical guides to the longitudinal research associated with the PD, which followed the teachers over two years. However, this study, which is only concerned with the teachers' ideas at entry, does not include the teachers' full beliefs about decision-making. Rather, this study considers three components of teachers' beliefs: What do teachers identify as a decision-making activity? Do teachers teach for decision-making? Also, how confident are they in their ability to teach this way? 


\subsection{Decision Making Framework}

In this section, I focus on decision-making frameworks. I start by discussing decision-making from the Svenson's [10] work examining the cognitive processes people engage in when they make decisions. I used Svenson's work as my primary guide because it provided a useful organization for understanding the varied kinds of decisions people engage in, and the behaviors people use to make decisions. I then extend this to look at both the how and what of decision-making as Lee \& Grace [11] emphasized these two sides of decision-making: 'decision-making as a process', which includes the procedures individuals use to make a decision; and 'decision-making as learning', which includes the abilities individuals need to make a 'good' decision.

\subsection{Decision-Making as Process}

Svenson's research in decision-making forms the basis of our understanding of how people make decisions. Based on his research, which is empirical and literature-based, he proposed the Differentiation and Consolidation Theory (DCT) of human decision-making. The overarching idea of this theory suggests decisions are made in a dual space: the pre- and post-decision. This simply means that when we start to make a decision we predict an outcome, the pre-decision [10]. However, experienced decision-makers are aware that the outcome of a decision, the post-decision, may not match the prediction. So decision-making is a process of considering multiple pre and post alternatives. This engagement in alternatives is an "active process, which involves both the use of decision rules, facts and attractiveness of representations-[10] (p. 144)." Consolidation after a decision is made, involves coming to terms with "the attractiveness of the representation". Said another way, the decision-maker rationalizes correctness of the decision. Details about the activities that take place during the DCT process are outlined in Table 1.

Svenson [12] also delineated decision levels that address the complexity of thinking needed to make a decision. The levels categorize decisions by the degree and conscious use of rules used in the differentiation stage. The levels range from 1 to 4 , with 1 being automatic/unconscious and 4 being complex and involving conscious and active employment of decision rules. A level 4 decision occurs when "the set of decision alternatives is not fixed nor is the set of attributes (on which the aspects [decision rules] are ordered) used to characterize them [12] (p. 255)." PBL and EDP should engage students in level 4 decisions; as such, this study is focused on the decision-making activities needed for a level 4 decision.

With experience people become better decision-makers, and being a better decision-maker is similar to being an effective learner. As better learners ideas, rules, processes, and procedures become automated, prior experiences and knowledge are used to establish and refine decision rules, and complex decisions become simplified into meta-rules, which effectively reduce the number of decisions. Svenson saw decision-making as a systematic search for and evaluation of possible outcomes through the application of rules and criteria [10].

Table 1. Stages and Activities in Decision-Making.

\begin{tabular}{|c|c|c|}
\hline Stage 1 Pre-Decision Stage & Stage 2 Differentiation Stage & Stage 3 Consolidation Stage \\
\hline $\begin{array}{l}\text { - Recognizing there is a problem } \\
\text { - } \\
\text { Identifying decision alternatives }\end{array}$ & $\begin{array}{ll}\text { - } & \text { Establishing criteria } \\
\text { - } & \text { Weighing pros and cons } \\
\text { - } & \text { Assessing available information } \\
\text { - } & \text { Gathering more information (inquiry) } \\
\text { - } & \text { Testing information in the situation } \\
& \text { Identifying new alternatives }\end{array}$ & $\begin{array}{l}\text { - Increasing confidence in decision } \\
\text { (which includes some of the same } \\
\text { activities as stage 2) } \\
\text { - } \begin{array}{l}\text { Minimizing regret } \\
\text { (negative outcomes) }\end{array}\end{array}$ \\
\hline
\end{tabular}

\subsection{Decision-Making as Learning}

Svenson [12] argued that much of the research on decision-making focused on level 3 decisions, which are geared towards the development of meta-rules and procedures, rather than level 4 decisions, 
which are focused on complex problems with no single defined correct answer. Level 4 decisions require the selection of the "best" alternative out of a set of suitable alternatives. In the psychological literature where Svenson was working, he found level 4 decision-making processes were under represented. The closest research base for level 4 decisions was in the socioscientific issues (SSI) literature. This literature also has the benefit of being focused on how students, typically in grades 7-12, engage in decision-making. A limitation of the SSI literature as a model for decision-making as learning is the interference of the emotional intensity typically found in the problem context of SSI lessons. This interference in the decision-making process is discussed below.

In the SSI literature, multiple researchers have found that students do not follow a systematic decision-making process [11,13-15]. Students in these cases were more likely to act on intuitive and emotion-based reasoning, rather than on a highly rational, systematic decision-making process $[13,14]$. Ullman [16] identified intuitive and rational decision-making depending upon the information students were drawing on to make their decisions. When students made decisions based on intuition or emotion Ullman [16], considered this as using weak information versus using strong (rational) information. Strong information included data, models, and content knowledge, while weak information included interpersonal relationships, behaviors, and judgments. Although both weak and strong information are important in decision-making, SSI teachers, and in this case teachers using EDP, were looking for students to use strong information, but students were more likely to use weak information.

Across the SSI research, teachers emphasized that they wanted students to learn to make decisions, as well as for the students to learn science through their decisions. In order to accomplish this, the authors provided a variety of 'decision-making templates'. Although there were differences in the templates, overall they were remarkably similar [11,14,15,17-19]. These templates summarized decision-making into three broad stages, which I have aligned with Svenson's $[10,12]$ DCT decision-making stages in Table 1.

In addition to the template mapped to decision-making theory, these ideas map closely to the EDP (for example Wan \& Krishnamurty [20]). Given this overlap, it is clear that integrating engineering into STEM teaching provides teachers with a useful mechanism to develop students' decision-making abilities.

Overall, there is consensus around the importance of both decision-making as a process and decision-making as learning. The decision-making process is adapted to fit the purpose of the decisions being made, whether they are socioscientific issues, designs choices, or personal needs; how we make the decision is vitally important. Enhancing students' decision-making abilities is the most essential component of developing critical thinking skills; one does not exist without the other [21], and therefore this enhancement should be an intentional educational aim for all teachers.

\section{Methods}

This study was part of a larger longitudinal study of the secondary science and mathematics teachers who participated in a two-year professional development focused on integrating engineering into their mathematics or science instruction. This study used the pre-program interview and survey data gathered as part of the larger study. Methodologically, the larger study used qualitative and quantitative data to understand how the teachers' beliefs and practices changed over the two years. However, the research reported here used only the initial (pre-program) interview and survey data. The interview was used to understand what possibilities teachers saw for decision-making in particular engineering instructional activities, whereas the survey asked the teachers to report their confidence with teaching activities where students are engaged in decision-making activities. All the data is reported with descriptive statistics.

\subsection{Context}

The PD program used a Challenge-Based Learning (CBL) [22] framework for the units and lessons the teachers designed. In CBL, the lesson begins with a societal challenge, such as public health or 
water security, and then the students and teacher collaboratively generate an essential question to address in order to respond to the larger challenge [22]. The essential question becomes the starting point for creating a solution to a more limited but still complex problem, which engaged the students in the use of EDP. In the program description the process was described in the following way: "by synthesizing CBL and EDP, the teachers use the challenge to get students engaged and interested in the program and then guide them to use the EDP to seek out multiple solutions" to meet a design problem [23].

\subsection{Participants}

The teachers who participated in the PD program came from a range of secondary schools including high-income suburban schools, high poverty urban schools, and mixed income rural schools. The teachers self-selected into the PD program by way of a partnership between the school districts and the hosting university. Over the duration of the PD program, approximately 100 teachers participated. From these 100 teachers, 16 volunteered to participate in the research component of the study. Table 2 includes basic information about the research participants who, as a group, represented the full program demographics, with the exception of an overrepresentation of suburban teachers in the research.

Table 2. Research Participant Distribution.

\begin{tabular}{lc}
\hline \multicolumn{1}{c}{ Characteristics } & Distribution \\
\hline Gender & \\
\hline Male & 4 \\
female & 12 \\
\hline Content Taught & \\
\hline Science & 9 \\
Math & 7 \\
\hline School Type & 3 \\
\hline Rural & 6 \\
Urban & 7 \\
Suburban & \\
\hline Grade Band Taught & 8 \\
\hline Middle (grades 6-8) & 8 \\
High School (grades 9-12) & \\
\hline Years Teaching Experience & 2 \\
\hline$<3$ & 6 \\
3-8 & 89
\end{tabular}

\subsection{Data Gathering}

The data for this study were gathered at the teachers' entry into the program as a baseline understanding of their beliefs and practices. The teachers were surveyed about their current instructional practices at the program orientation. Individual interviews were arranged with each research participant in the week after the program orientation and prior to the start of the program. Interviews were arranged at the convenience of the teachers' and were audiotaped and transcribed by an external company.

The interview followed a set protocol, called the Conceptions of Teacher Engineering (CTE). The CTE used scenarios about potential teaching and learning situations, to which the teachers responded, based on their interpretation of the situation and their beliefs about the roles of the people presented. The protocol was based on Hewson and Hewsons' [24]) Conceptions of Teaching Science 
protocol. The Current Instructional Practices survey was a self-report survey about the teachers' use of and confidence with different student-centered instructional practices. The survey was developed specifically for the purpose of the PD program as a measure of change in the teachers' practices and confidence over the course of the PD. For this research, the survey was used to establish the teachers' baseline beliefs and practices only. The survey was sent to an external evaluation consultant to determine content its validity. For the purposes of this study, the survey questions were used as proxy decision-making activities and aligned to pre-decision, differentiation, or consolidation stages.

The survey (see Table 3 in results) used a Likert scale from 1 to 4 , with one being never used or not confident and four being used regularly or very confident. Table 4 shows the survey items, aligned to their corresponding decision-making stage. This alignment to decision-making stages allows for a direct comparison of the survey and interview results.

Table 3. Summary Survey Responses.

\begin{tabular}{|c|c|c|c|}
\hline \multirow{3}{*}{ Stage Code } & Question: & \multirow{3}{*}{ A Mean Use } & \multirow{3}{*}{ B Mean Confidence } \\
\hline & $\begin{array}{l}\text { A. To what extent do you currently incorporate } \\
\text { the practices: }\end{array}$ & & \\
\hline & $\begin{array}{l}\text { B. Indicate your current level of confidence } \\
\text { implementing these practices: }\end{array}$ & & \\
\hline \multirow[t]{2}{*}{1} & $\begin{array}{l}\text { Guide students to break complex global problems } \\
\text { into their local and more actionable components }\end{array}$ & 1.75 & 2.08 \\
\hline & Guide students in refining problems & 2.25 & 2.45 \\
\hline \multirow{5}{*}{2} & $\begin{array}{l}\text { Guide students in planning investigations to better } \\
\text { understand different components of problems }\end{array}$ & 2.67 & 2.42 \\
\hline & $\begin{array}{l}\text { Provide opportunities for students to gather } \\
\text { information about problems or issues of importance }\end{array}$ & 2.25 & 2.72 \\
\hline & $\begin{array}{l}\text { Provide students with opportunities to explore } \\
\text { multiple solution pathways for problems }\end{array}$ & 2.67 & 2.58 \\
\hline & $\begin{array}{l}\text { Guide students in weighing the pros and cons of } \\
\text { different solution pathways }\end{array}$ & 2.58 & 2.5 \\
\hline & $\begin{array}{l}\text { Provide students with opportunities to test their } \\
\text { solution pathways }\end{array}$ & 2.25 & 2.67 \\
\hline \multirow{2}{*}{3} & $\begin{array}{l}\text { Guide students in evaluating the results of their } \\
\text { solution pathways }\end{array}$ & 2.17 & 2.5 \\
\hline & $\begin{array}{l}\text { Provide students with opportunities to refine and } \\
\text { retry a solution pathway }\end{array}$ & 2.17 & 2.75 \\
\hline 0 & $\begin{array}{l}\text { Provide opportunities for students to take } \\
\text { responsibility for the decisions they made about the } \\
\text { processes used in solving complex problems }\end{array}$ & 2.17 & 2.58 \\
\hline
\end{tabular}

\subsection{Data Analysis}

The author was solely responsible for data coding and used the framework detailed in Table 2 as the analytical framework for coding the data. The transcripts were initially coded into the broad category of decision stage based on the description of the activity. From there, the decision-making activities were coded a second time into within-stage sub-codes. Decisions that did not immediately code into a specific stage were coded as 0 . These were reconsidered after the full data set was coded and moved, if appropriate, to another stage and sub-code, if not left as stage 0 . The frequency of each sub-code occurrence across the 16 interviews is reported with the number of participants who mentioned each sub-code and the average frequency for those teachers.

In order to understand the kinds of statements that coded into each stage and sample sub-codes, example statements from the interviews are in Table 4. Bolded within each quote are the terms that were essential to determining the sub-category. These examples capture the ideas used by the participants, although the specific language varied from person to person. 
Table 4. Codes and Example Teacher Responses.

\begin{tabular}{|c|c|c|}
\hline Stage Code & Sub-Code & Teacher Example \\
\hline \multirow{3}{*}{1} & Problem identification & The students have been given a challenge. They have a problem. \\
\hline & Problem Identification & $\begin{array}{l}\text { So if you're just following a rigid recipe, there's no creativity or } \\
\text { freedom there. So I-with it being so rigid, I would call that not } \\
\text { necessarily }\end{array}$ \\
\hline & Alternate solutions & $\begin{array}{l}\text { I think they'll have to identify what the problem is, um, to get } \\
\text { some possible solutions, do some brainstorming. }\end{array}$ \\
\hline \multirow{3}{*}{2} & Test Revise & $\begin{array}{l}\text { And then they are, um, going to implement their solution. ... } \\
\text { And then they're going to, I think, implement their solution. } \\
\text { They're going to decide if they need to make some revisions. }\end{array}$ \\
\hline & Pro/cons & $\begin{array}{l}\text { they have to go through their own process and refine it and come } \\
\text { up with, um, pros and cons of their own plan }\end{array}$ \\
\hline & Implied test & $\begin{array}{l}\text { I think as long as that trial and error is guided in some way, as } \\
\text { long as it was part of their design plan or-but I think that's } \\
\text { where a lot of the learning comes in. }\end{array}$ \\
\hline \multirow[b]{2}{*}{3} & Justify & $\ldots$ because it's tying it into some bigger problem \\
\hline & Evaluate & $\begin{array}{l}\text {... communicate come up with a product and you know, it's } \\
\text { authentic and it, it's going out to the community and, and then } \\
\text { they may have to add on or revise from there }\end{array}$ \\
\hline \multirow{2}{*}{0} & Teacher leading & $\begin{array}{l}\text { I guess engaging in the process. I mean, they, they do have to } \\
\text { follow step-by-step procedure. }\end{array}$ \\
\hline & Generalized skills & $\begin{array}{l}\text { I think that's just a way of um, figuring out or strategizing as } \\
\text { your way through something. }\end{array}$ \\
\hline
\end{tabular}

The survey responses are reported as average scores for the teachers. Although the average scores with such a narrow range of choice does not provide much detail to the understanding of decision-making, two ideas were considered. The first being, how did use and confidence of the different aspects of decision-making compare, and second, how did the use and confidence compare with the teachers beliefs about teaching in the interviews.

It is important to note when comparing the stage 0 decisions that the alignment between the survey (see Table 3) and the interview sub-codes do not appear to be a good match. However, what was considered when coding interviews into stage 0 included: (a) Were the students making the decisions or were the decisions being determined by the teacher (at any point in the process)? and (b) Was the statement too open-ended to be able to determine the kinds of processes involved? In the survey, the 0 code was a general statement about students' decision making rather than an indicator of a specific activity in a decision-making stage.

\section{Results}

The survey responses indicate that most of the teachers believed at the start of the program that they were not engaging their students in learning activities that offered them practice with decision-making; also, the teachers were not confident in their ability to lead these learning activities. Table 3 below details the average of the scores for the 16 teachers on all questions.

In response to the comparison between the teachers use and confidence with specific practices, in all but three instances the teachers felt more confident in their ability to teach a decision-making activity than to implement such an activity, according to their reports. The three items where the teachers were less confident are essential steps in the differentiation process, which create the rational basis for evaluating possible outcomes. These steps involved deconstructing a decision into the possible alternative outcomes, establishing criteria for evaluating, and then systematically evaluating possible outcomes. Of the five differentiation steps included in the survey, the teachers lacked confidence working with students on clarifying the important competing ideas when making a decision. On the 
other hand, the activities in which the teachers were more confident in their ability were generally observable activities that engaged students with resources and materials.

Additionally, the teachers believed they engaged their students less often in stage 1 (pre-decision) and in stage 3 (consolidation) activities in decision-making, activities that require students to engage in high-level thinking. This suggests that teachers believe they provide their students with opportunities to practice clear procedural, and observable, steps in making a decision, but are not particularly strong in supporting the students thinking about their internal intellectual processes. The teachers believed they did not make clear to students why they were making the decisions and/or clarifying the potential impact of a decision.

Table 5 displays the coded interview data into stages and sub-codes. The table includes the frequencies of coded responses for the decision stage and sub-code, the number of teacher participants coded for each sub-code at least once, and the average sub-code mention per participant based on the total participant population of 16 .

Table 5. Stage and Sub-code Interview Response \& Frequencies.

\begin{tabular}{|c|c|c|c|c|}
\hline Stage Code & Sub-Codes & Freq. & $\mathbf{N} *$ & Mean \\
\hline \multirow{3}{*}{1} & - Problem identification & 138 & 16 & 8.63 \\
\hline & - Alternate solutions & 66 & 13 & 5.08 \\
\hline & STAGE 1 TOTAL & 204 & - & 12.75 \\
\hline \multirow{7}{*}{2} & - Establishing criteria & 20 & 13 & 1.54 \\
\hline & - Weighing pros and cons & 16 & 10 & 1.60 \\
\hline & - Assessing available information & 28 & 12 & 3.93 \\
\hline & - Gathering more information & 44 & 15 & 2.93 \\
\hline & - Testing information in the situation & 78 & 16 & 4.88 \\
\hline & - Identifying new alternatives & 38 & 10 & 3.80 \\
\hline & STAGE 2 TOTAL & 224 & - & 14.0 \\
\hline \multirow{3}{*}{3} & - Increasing confidence in decision-make decision explicit & 22 & 10 & 2.20 \\
\hline & - Minimize regret-communicate decision to others & 32 & 12 & 2.67 \\
\hline & STAGE 3 TOTAL & 52 & - & 3.25 \\
\hline \multirow{3}{*}{0} & - General problem solving, critical thinking & 20 & 8 & 2.5 \\
\hline & - Teacher led & 23 & 10 & 2.3 \\
\hline & STAGE 0 TOTAL & 43 & - & 2.69 \\
\hline
\end{tabular}

* The $\mathrm{N}$ indicates the number of teachers who had at least one code in this category.

Table 5 indicates that the teachers believed it was important to spend time engaging their students in stage 1 pre-decision activities, even though this appears to be in conflict with their self-reported confidence for engaging students in problem clarification. Although the overall number of coded comments in stage 2 was higher, this is simply a result of stage 2 being more complex and with more components. The fact that the teachers consistently suggested problem clarification was an important aspect of teaching with engineering and supporting student decision-making is an interesting contrast to their reported teaching practices, and raises questions about how they will handle this during implementation.

Looking specifically within stage 2, it is not surprising this had a high number of references; first, as mentioned above, it includes the most individual steps, but this is also because of the teachers' reliance on having students test solutions. This is a very comfortable teaching activity for science and mathematics teachers, given the disciplines' reliance on empirical testing and modeling to validate ideas and decisions. The teachers' reliance on testing was both supported and contradicted by the teachers' self-reporting in the surveys. The teachers reported frequently engaging their students in planning investigations and providing opportunities for students to explore multiple solution pathways, but at the same time they reported not providing their students with frequent opportunities for them to carry out, evaluate, and refine investigations.

Based on the interviews and the surveys, the teachers believed they did not give their students many opportunities to evaluate or judge the quality of their decisions, nor did they mention supporting 
students in the pre-requisite activities to effectively judge their decision. The teachers rarely helped students establish criteria from stage 2 allowing them to evaluate their decisions in stage 3 . In instances when the teachers mentioned students evaluating and consolidating their decisions, it was through the loose alignment of presenting the information to other stakeholders or peers. They relied on a form of external validation rather than considering internal satisfaction with the decisions made.

Overall, the interviews and surveys suggested the teachers were more familiar with activities in which the students were doing through data gathering and/or the manipulation of materials than they were in working with students on internal and cognitive activities, such as setting criteria and evaluating ideas and outcomes. This suggests that the teachers' believed that students' actions are effective representations of thinking and decision-making.

\section{Implications}

This initial exploration into teachers' initial ideas about the opportunities provided for decision-making when teaching with engineering begins an exploration into understanding the impact of adding engineering design into traditional science and mathematics instruction. The Engineering Design Process provides a reasonable mechanism for teachers to enhance students' decision-making, and the newness of this form of instruction provides an opportunity to extend teachers' current practices and focus more explicitly on decision-making. However, in order to capitalize on the addition of engineering to improve student decision-making, we need to understand what teachers identify as a decision-making opportunity so we can build and scaffold the new teaching practice. In this study, the teachers focused on the activities of decision-making in engineering that were different from their current instructions, which consisted of problem identification, outcome evaluation, and refinement. This was not unexpected, as teachers may have had little experiences with EDP at the time of the interview. However, what it does suggest is that teachers believed students' successful engagement in the observable steps of decision-making in the engineering problems meant that students were effectively engaging in non-observable cognitive activities as well. Teachers will struggle to develop these no-observable cognitive activities if they do not identify them and provide specific support for students to master them.

This initial picture of teachers' beliefs is, of course, incomplete, and needs to be extended to understand how the identified activities translate into teaching practices. (After which, as Guskey [9] suggests, we need to understand the impact of the students' performance on the teachers' beliefs as they continue to use engineering design and develop their students' decision-making skills). During implementation, we need to know: Do teachers implicitly accept the idea that their students' external performance is a good proxy for intellectual activities, or do they include explicit instructions for these activities? These are important next steps if we are to consider the inclusion of engineering design as an appropriate mechanism for supporting students learning through decision-making.

\section{Conclusions}

In considering the previous literature on teachers' beliefs about student decision-making, the most extensively researched area was in the socioscientific issues literature. Science teachers who used SSIs for their students stressed the importance of their students' ability to learn how to make good decisions, as well as their ability to learn science through their decisions. What is clear from this research is that these secondary STEM teachers were not yet able to articulate this dual role for integrating engineering. Rather, the teachers in this study did not focus on the students learning to make decisions; in fact, they simply replaced decision-making with EDP and focused on whether the students were engaged in the design process. At this early stage of understanding, they did not generalize the engineering design process into a set of beliefs about developing students' decision-making or even specifically encouraging students to be active decision-makers. It will be interesting to see whether these teachers, and others, begin to see the need to systematically support students in learning to make decisions, 
as well as the need for the explicit value of EDP as a way to engage students in making decisions, as they become more familiar with integrating engineering and EDP into their instruction.

Acknowledgments: This research was supported by a Mathematics and Science Partnership grant from the National Science Foundation [grant number 1102990]. Funding has also been received to cover the costs to publish in open access.

Conflicts of Interest: The author declare no conflict of interest.

\section{References}

1. Cone, N. Using Problem-Based Learning to contextualize the science experiences of urban teachers and students. In Multicultural Science Education: Preparing Teachers for Equity and Social Justice; Atwater, M., Russell, M., Butler, M., Eds.; Springer: New York, NY, USA, 2014; pp. 159-173.

2. National Research Council. A Framework for K-12 Science Education: Practices, Crosscutting Concepts, and Core Ideas; Committee on a Conceptual Framework for New K-12 Science Standards; Board on Science Education, Divisions of Behavioral and Social Sciences and Education; The National Academies Press: Washington, DC, USA, 2012.

3. Gordon, P.; Rogers, A.; Comfort, M.; Gavula, N.; McGee, B. A taste of problem-based learning increases achievement of urban mibority middle school students. Educ. Horiz. 2001, 79, 171-175.

4. Stefanou, C.; Perencevich, K.; DiCintio, M.; Turner, J. Supporting autonomy in the classroom: Ways teachers encourage student decision making and ownership. Educ. Psychol. 2004, 39, 97-110. [CrossRef]

5. Richardson, V.; Placier, A. Teacher Change. In Handbook of Research on Teaching: Fourth Edition; Richardson, V., Ed.; American Educational Research Association: Washington, DC, USA, 2001; pp. 905-947.

6. Richardson, V. The role of attitudes and beliefs in learning to teach. In Handbook of Research on Teacher Education, Edition: Second Edition; Sikula, J., Ed.; American Education Research Association: Washington, DC, USA, 1996; pp. 102-119.

7. Somekh, B. Factors affecting teachers' pedagogical adoption of ICT. In International Handbook of Information Technology in Primary and Secondary Education; Voogt, J., Knezek, G., Eds.; Springer: New York, NY, USA, 2008; pp. 449-460.

8. Ertmer, P.; Ottenbreit-Leftwich, A. Teacher technology change: How knowledge beliefs and culture intersect. In Proceedings of the Annual Meeting of the American Education Research Association, San Diego, CA, USA, 13-17 April 2009.

9. Guskey, T. Professional development and teacher change. Teach. Teach Theory Pract. 2002, 8, 381-391. [CrossRef]

10. Svenson, O. Differentiation and consolidation theory of human decision making: A frame of reference for the study of pre- and post-decision processes. Acta Psychol. 1992, 80, 143-168. [CrossRef]

11. Lee, Y.; Grace, M. Students' reasoning and decision making about a socioscientific issue: A cross-context comparison. Sci. Educ. 2012, 96, 787-807. [CrossRef]

12. Svenson, O. Decision making and the search for fundamental psychological regularities: What can be learned from a process perspective? Organ. Behav. Hum. Decis. Process. 1996, 65, 252-267. [CrossRef]

13. 1Hsu, Y.; Lin, S. Prompting students to make socioscientific decisions: Embedding metacognitive guidance in an e-learning environment. Int. J. Sci. Educ. 2017, 39, 964-979.

14. Akerblom, D.; Lindahl, M. Authenticity and the relevance of discourse and figured worlds in secondary students' discussion of socioscientific issues. Teach. Teach. Educ. 2017, 65, 205-214. [CrossRef]

15. Acar, O.; Lutfullah, T.; Roychoudhury, A. Student difficulties in socio-scientific arguementation and decision-making research findings: Crossing the boarders of two research lines. Int. J. Sci. Educ. 2010, 32, 1191-1206. [CrossRef]

16. Ullman, D. Robust decision-making for engineering design. J. Eng. Des. 2001, 12, 3-13. [CrossRef]

17. Ratcliff, M. Student decision-making about socio-scientific issues within the science curriculum. Int. J. Sci. Educ. 1997, 19, 176-182.

18. Grace, M. Developing high quality decision-making discussions about biological conservation in a normal classroom setting. Int. J. Sci. Educ. 2009, 31, 551-570. [CrossRef] 
19. Brew, A. Understanding the scope of undergraduate research: A framework for curricular and pedagogical decision-making. High. Educ. 2013, 66, 603-618. [CrossRef]

20. Wan, J.; Krishnamurty, S. Learning-based preference modeling in engineering design decision-making. J. Mech. Des. 2001, 123, 191-198. [CrossRef]

21. Ulucinar, U.; Aypay, A. A model of decision-making based on critical thinking. Educ. Sci. 2016, 41, $251-268$.

22. Apple, Inc. Challenge Based Learning: A Classroom Guide. 2010. Available online: https://images.apple. com/education/docs/CBL_Classroom_Guide_Jan_2011.pdf (accessed on 7 July 2017).

23. CEEMS: The Cincinnati Engineering Enhanced Mathematics and Science Program, 1102990 Annual Report. Available online: Https: / / reporting.research.gov/rppr-web/rppr?executiong=els2 (accessed on 31 July 2017).

24. Hewson, P.; Hewson, M. Analysis and use of a task for identifying conceptions of teaching science. J. Educ. Teach. 1989, 15, 191-209. [CrossRef]

(C) 2018 by the author. Licensee MDPI, Basel, Switzerland. This article is an open access article distributed under the terms and conditions of the Creative Commons Attribution (CC BY) license (http://creativecommons.org/licenses/by/4.0/). 